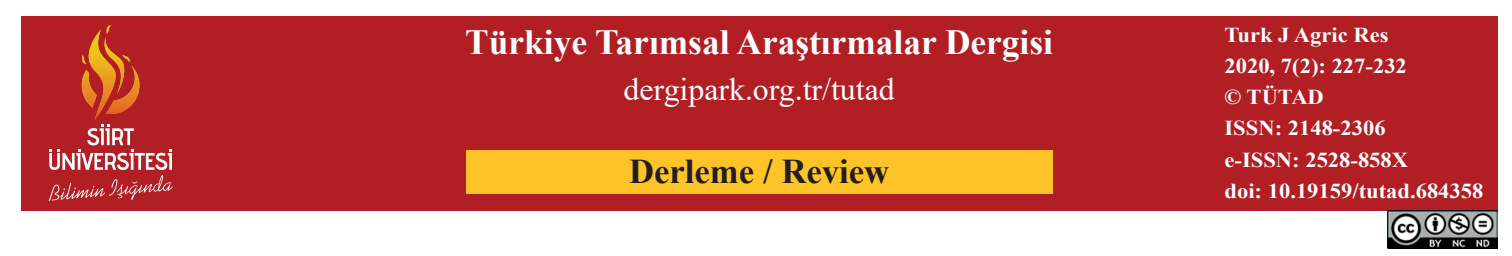

\title{
Kanatlı Hayvan Beslemede Jatropha (Jatropha curcas) Kullanılması
}

\author{
Behlül SEVIM1, Tugay AYAŞAN ${ }^{2 *}$ \\ ${ }^{I}$ Aksaray Üniversitesi, Eskil Meslek Yüksekokulu, Veterinerlik Bölümü, Aksaray, TÜRKIYE \\ ${ }^{2}$ Osmaniye Korkut Ata Üniversitesi, Kadirli Uygulamalı Bilimler Yüksekokulu, Organik Tarım Işsletmeciliği Bölümü, Osmaniye, TÜRKIYYE
}

\begin{tabular}{ll}
\hline \multicolumn{1}{c}{ Geliş Tarihi/Received: 04.02.2020 } & Kabul Tarihi/Accepted: 30.05 .2020 \\
\hline ORCID ID (Yazar sırasina göre / by author order) \\
\hline (D) orcid.org/0000-0003-2996-3241 (D) orcid.org/0000-0001-7397-6483 \\
"Sorumlu Yazar/Corresponding Author: tugayayasan@osmaniye.edu.tr
\end{tabular}

Öz: Kanatlı hayvan yemlerinde soya küspesi ve balık unu gibi protein kaynağı olarak kullanılan yem bileşenlerinin, piyasa fiyatlarındaki dengesizlik ve yukarı yönlü artış sonucunda daha ucuz alternatif kaynaklara duyulan ihtiyaç artmıştır. Bu alternatif yem kaynaklarından birisi olan Jatropha (Jatropha curcas) bitkisi, biyoyakıt kaynağı olarak son yıllarda popülaritesini arttıran, protein içeriği oldukça yüksek olan sütleğen (Euphorbiaceae) familyasına ait bir bitkidir. Bu derlemede Jatropha (J. curcas) bitkisinin besin madde içeriği ile kanatlı hayvan beslemede kullanılabilirliği araştırılmıştır.

Anahtar Kelimeler: Jatropha, besin madde kompozisyonu, etlik piliç, yumurta tavuğu, bıldırcın

\section{The Use of Jatropha (Jatropha curcas) in Poultry Nutrition}

\begin{abstract}
As a result of the imbalance and upward increase in market prices of feed ingredients used as protein sources such as soybean meal and fish meal in poultry feeds, the need for cheaper alternative sources has increased. Jatropha (Jatropha curcas), one of these alternative feed sources, is a plant of Euphorbiaceae family which has increased its popularity in recent years as a biofuel source. In this review, nutrient content of Jatropha (J. curcas) plant and its usability in poultry feeds were investigated.
\end{abstract}

Keywords: Jatropha, nutrient composition, broiler, laying hen, quail

\section{Giriș}

Jatropha curcas, sütleğen familyası (Euphorbiaceae)'na ait çiçekli bir bitki türüdür. Özellikle Güney ve Orta Amerika başta olmak üzere dünya çapında $330.000 \quad \mathrm{~km}^{2}$ alanda yetiştirilmektedir. Biyoyakıt olarak kullanılmak üzere yetiştirilen Jatropha'nın yan ürünü olan küspedeki ham protein (HP) oran1 dikkat çekmektedir. Bir ton Jatropha tohumundan 200300 litre biyoyakıt üretilirken, 700-800 kg küspe elde edilmektedir (Saeed ve ark., 2017).

Jatropha, her yıl ürün verebilen, uzun ömürlü bir bitki olup, boyu $3 \mathrm{~m}$ kadar uzayabilmektedir. Jatropha tohumları yaklaşık \% 35-50 oranında HP, \% 60 ham yağ (HY) içermekte olup; mineral ve esansiyel amino asitler bakımından zengindir.
Jatropha'nın besin madde içeriği, bitkinin farkı kısımlarında (tohum, kök, kabuk ve yaprak) farklı oranlarda bulunmaktadır. Meyvesinin içinde bulunan $2 \mathrm{~cm}$ boyundaki çekirdeğinde \% $35-40$ oranında HY bulunur. Aynı zamanda dengeli bir protein içeriğine de sahiptir. Tropik iklimlerde tarımı yapılan Jatropha bitkisi öncelikle bioyakıt üretiminde kullanılmak için yetiştirilmekte olup; öncelik sırasına göre ilk olarak biodizel, ikincil olarak da sabun gibi ürünlerin yapımında etkin rol oynamaktadır (Jongschaap ve ark., 2007; Pomalégni ve ark., 2018).

Bu derleme çalışmasında; Jatropha bitkisinin besin maddesi kompozisyonu, kullanım şekilleri ile hayvan beslemedeki önemi üzerinde durulmuştur. 


\section{Jatropha Bitkisinin Besin Maddesi Kompozisyonu}

Jatropha'nın besin madde kompozisyonu ile ilgili olarak farklı araştırıcılar, farklı içerik oranları bildirmişlerdir. Besin madde içeriklerinin birbirlerinden farklı olması, çeşit, yetiştirme tekniği, yetiştirilen yer, bölge, ülke, analiz yöntemlerinin ve kullanılan metotların farklı olması vb. birçok faktörlere göre değişiklik göstermektedir. Besin maddesi oran1, Jatropha bitkisinin farklı kısımlarına (tohum, kök, kabuk ve yaprak) göre de değişim göstermektedir.

Abou-Arab ve Abu-Salem (2010), J. curcas tohumlarının protein ( $\% 32.88)$, yağ ( $\%$ 27.36) ve karbonhidrat (\% 30.11) bakımından iyi bir kaynak olduğunu; tohumların çeşitli mikro [Mangan (Mn), demir (Fe) ve çinko ( $\mathrm{Zn}$ ) içerikleri sırasıyla; 28.37 $\mathrm{mg} \mathrm{kg}-1,0.38 \mathrm{mg} \mathrm{kg}^{-1}$ ve $47.13 \mathrm{mg} \mathrm{kg}^{-1}$ ] ve makro [Potasyum (K), kalsiyum $(\mathrm{Ca})$, sodyum $(\mathrm{Na})$, magnezyum $(\mathrm{Mg})$ ve fosfor $(\mathrm{P})$ düzeyleri sirasıyla; $103.13 \mathrm{mg} \mathrm{kg}^{-1}, 34.21 \mathrm{mg} \mathrm{kg}^{-1}, 8.44 \mathrm{mg} \mathrm{kg}$, $109.89 \mathrm{mg} \mathrm{kg}^{-1}$ ve $185.17 \mathrm{mg} \mathrm{kg}^{-1}$ ] elementler bakımından zengin olduğunu; tohumların fitik asit, tripsin inhibitör aktivitesi, toplam fenol ve saponin düzeylerinin sırasıyla $52.59 \mathrm{mg} 100 \mathrm{~g}^{-1}, 25.58 \mathrm{mg}$ $100 \mathrm{~g}^{-1}, 39.95 \mathrm{mg} 100 \mathrm{~g}^{-1}$ ve $1.51 \mathrm{mg} 100 \mathrm{~g}^{-1}$ olduğunu tespit etmişlerdir.

Sumiati ve ark. (2009), fermente ederek kullandıkları Jatropha küspesinde HP oranını $\%$ 22.39, toplam enerjiyi $3984 \mathrm{kcal} \mathrm{kg}^{-1}$ olarak bildirirken; ham kül (HK) oranını \% 5.95 olarak tespit etmiştir. Başka bir araştırmada Obun ve ark. (2016), Jatropha küspesinde sıcaklık işlemi uygulanmadığında HP oranını \% 30.21, ham selüloz (HS) oranını \% 42.00, HK oranını \% 5.76 olarak bildirmişlerdir. Bir diğer araştırmada ise Annongu ve ark. (2010), Jatropha'nın tohumlarında yaklaşık $\% \quad 60$ yağ olduğunu belirtmişlerdir.

Yakubu ve ark. (2017), preslenmiş ve fermente edilmiş Jatropha küspesinde besin madde içeriklerini araştırdıkları çalışmalarında, preslenmiş Jatropha küspesinde \% 89.8 kuru madde (KM), \% $32.61 \mathrm{HP}, \% 7.33 \mathrm{HK}, \% 11.34$ HY, \% 4.13 HS, $5177.82 \mathrm{kcal} \mathrm{kg}^{-1}$ metabolik enerji (ME) olduğunu bildirirken; fermente edilmiş Jatropha tohumu küspesinde \% $92.55 \mathrm{KM}$, \% 42.38 HP, \% 8.34 HK, \% 34.21 HY, \% 2.10 HS ve $3329.72 \mathrm{kcal} \mathrm{kg}^{-1} \mathrm{ME}$ olduğunu belirtmişlerdir. Ayrıca anti besinsel faktör olarak tanin, tripsin olarak inhibitör, saponin ve forbolester (phorbol ester ) içerdiğini de ifade etmişlerdir. Aynı araştırıcılar fermente işleminde, toplanan tohumların tozdan arındırıldığını, $3 \mathrm{kez}$ pişirildiğini, pişmiş tohumların suyunun süzüldüğünü, doğal fermantasyonun gerçekleşmesini sağlamak için polietilen ile kaplı jüt torbalarda paketlendiğini ve fermantasyon işleminin 72 saat sürdüğünü ifade etmişlerdir.

Saeed ve ark. (2017) tarafindan yürütülen Jatropha ve soya fasulyesi küspesi (SFK)'nin kimyasal kompozisyonunun karşılaştırıldı̆̆ çalışmanın sonuçları Tablo 1'de verilmiştir.

Tablo 1. Jatropha ve soya fasülyesi küspesi (SFK)'nin kimyasal kompozisyon bakımından karşılaştırılması (\% KM) (Saeed ve ark., 2017)

\begin{tabular}{lccc}
\hline Parametreler, \% & $\begin{array}{c}\text { Nijerya } \\
\text { Jatropha } \\
\text { küspesi }\end{array}$ & $\begin{array}{c}\text { Meksiko } \\
\text { Jatropha } \\
\text { küspesi }\end{array}$ & SFK \\
\hline HP & 56.10 & 64.40 & 46.50 \\
Kül & 9.60 & 9.80 & 6.40 \\
Lipid & 0.80 & 1.00 & 1.80 \\
ADF & 5.60 & 5.70 & 12.20 \\
NDF & 8.90 & 9.10 & 17.20 \\
Brüt enerji, $\mathrm{MJ} \mathrm{kg}^{-1}$ & 17.90 & 18.00 & 19.40 \\
\hline
\end{tabular}

ADF: Asit deterjanda çözünmeyen lif (Acid Detergent Fibre), NDF: Nötral deterjanda çözünmeyen lif (Neutral Detergent Fibre)

Jatropha tohumu yağ açısından zengindir. Özelikle çekirdek kısmında yağ oranı \% 58.1'e kadar çıkmaktadır. Meyve ve kabuk kısmında ise yağ ihmal edilecek kadar düşüktür. Meyve kısmında KM oranı \% 92'ye kadar çıkarken tohumda KM oranı \% 97'ye ulaşmakta; çekirdekte de maksimum sinır \% 98.7 olarak gerçekleşmektedir.

Nesseim ve ark. (2017), J. curcas'ın besin madde içeriğini inceledikleri çalışmalarında; \% 96.1 KM, \% 95.2 organik madde (OM), \% 25.9 HP, \% 55.5 HY, \% 11.6 HS, \% 4.8 HK, \% 2.4 azotsuz öz madde (NÖM), $5747 \mathrm{kcal} \mathrm{kg}^{-1} \mathrm{ME}$ içerdiğini tespit etmişlerdir. Michael ve ark. (2019) da farklı işleme metotlarının Jatropha küspesinin besin madde, mineral kompozisyonu ile vitamin içeriği üzerine etkin rol oynadığını ifade etmişlerdir.

Jatropha ve SFK'nın aminoasit içeriği birbirine yakın olup; SFK ile karşılaştırıldığında lizin, glutamik ve arginin aminoasitleri bakımından birbirlerinden farklılık gösterirler. Glutamik asit ve aspartik asit SFK'da en yüksek değeri alırken; farklı Jatropha küspelerinde de benzer sonuçlar bulunmuştur. Farklı Jatropha küspesi ile SFK'nın aminoasitler bakımından karşılaştırılması Tablo 2'de verilmiştir.

\section{Jatropha'nın Kullanım Şekilleri, Tıbbi Kullanımları}

Jatropha'yı oluşturan yaprak, tohum ve kabuklar, geleneksel tıp ve veterinerlikte uzun zamandan beri kullanılmaktadır (Asuk ve ark., 2015). 
Tablo 2. Farklı Jatropha küspeleri ile soya fasülyesi küspesi (SFK)'nin aminoasitler bakımından karşılaştırılması (Saeed ve ark., 2017)

\begin{tabular}{lccc}
\hline Amino asitler, \% & $\begin{array}{c}\text { Jatropha } \\
\text { küspesi }\end{array}$ & $\begin{array}{c}\text { Meksiko } \\
\text { Jatropha } \\
\text { küspesi }\end{array}$ & SFK \\
\hline Lisin & 4.28 & 3.40 & 6.08 \\
Lösin & 6.94 & 7.50 & 7.72 \\
İsolösin & 4.53 & 4.85 & 4.62 \\
Metionin & 1.91 & 1.76 & 1.22 \\
Sistin & 2.24 & 1.58 & 1.70 \\
Fenilalanin & 4.34 & 4.89 & 4.84 \\
Tirosin & 2.99 & 3.78 & 3.39 \\
Valin & 5.19 & 5.30 & 4.59 \\
Histidin & 3.30 & 3.08 & 2.50 \\
Treonin & 3.96 & 3.59 & 3.76 \\
Serin & 4.80 & 4.82 & 5.67 \\
Glutamik asit & 14.68 & 15.91 & 16.90 \\
Aspartik asit & 9.49 & 9.92 & 11.30 \\
Prolin & 4.96 & 3.80 & 4.87 \\
Glisin & 4.92 & 4.61 & 4.01 \\
Alanin & 5.21 & 4.94 & 4.23 \\
Arjinin & 11.80 & 12.90 & 7.13 \\
Triptofan & 1.31 & - & 1.24 \\
Alanin & 5.21 & 4.94 & 4.23 \\
\hline
\end{tabular}

Jatropha lateksi, kanserli olmayan ajanlar olarak önemli bir rol oynayan jatrofin, curcain ve jatropham gibi alkaloidleri içermekte olup; köklerinin yılan ısırmaları için bir panzehir olarak da kullanıldığı bilinmektedir.

Jatropha yağı, uzun zamandır farklı deri hastalıklarının tedavisinde kullanılmakta olup (Marroquin ve ark., 1997); Jatropha kernel yağının içermiş olduğu \% 36 düzeyindeki linoleik asit içeriği, deri tedavisi için ilgi çekmektedir. Bu bitkinin fitokimyasal içeriği, kullanılan çözücülerden bağımsız olarak yapraklarda en yüksek, köklerde ise en düşüktür. J. curcas'ın tüm parçaları (yaprak, gövde kabuğu ve kabuk) özellikle de yaprak, flavonoidler ve polifenoller bakımından zengin bir yapı göstermektedir. $\mathrm{Bu}$ fitokimyasalların anti-oksidatif aktiviteler, alerjilere karşı koruma, trombosit agregasyonu, inflamasyon, hepatik toksisite mikropları, ülserler, virüsler ve tümörler ile ilgili olduğu bildirilmektedir (Gutierrez-Orozco ve Failla, 2013; Syed ve ark., 2013).

\section{Jatropha Bitkisi ve Antibesinsel Faktörler}

Jatropha bitkisi; alkaloidler, terpenoidler, taninler, saponinler, siyanogenikler, glikozidler gibi farklı toksinler üretirler (Makkar ve Becker, 1997). $J$. curcas küspesi, ihmal edilebilir miktarda toplam fenoller bulundurmakta olup, \% 0.02-0.04 arasinda taninler içermektedir (Cheeke, 1998).

Jatropha bitkisinde pek çok toksik ve antinutrisyonel faktörler bulunması nedeniyle, bunların olumsuz etkisini azaltmak ve yemden yararlanmayı iyileştirmek için farklı işlemler uygulanmaktadır. Bu metotlar, biyolojik, fiziksel ve kimyasal metotlar olup; bunlar arasinda etanol uygulamas1, metanol uygulamas1, $121{ }^{\circ} \mathrm{C}^{\prime}$ de 20 dakika sıcaklıkla işlem uygulaması, $\mathrm{CaOH}$ (\% 2), fermantasyon gibi uygulamalar göze çarpmaktadır (Heuze ve ark., 2016). Fiziksel ve kimyasal olarak işlem görmüş Jatropha küspesinin etlik piliçlerin performansına olan etkisini araştıran Pasaribu ve ark. (2010), fiziksel ve kimyasal işleme tekniğinde her ikisinin birlikte uygulanmasının Jatropha küspesinin işlenmesinde en iyi teknik olduğunu, diğer tekniklerle karşılaştırıldığında, etlik piliçlerin daha iyi performans gösterdiklerini gözlemlemişlerdir.

J. curcas'ın etlik piliçlerdeki etkisinin araştırıldığı bir başka çalışmada (Ojo ve ark., 2013), J. curcas katkısının hepatotoksik ve neprotoksik olduğu, küçük miktarlarda bile kullanıldığında kan sirkülasyonunu etkileyebileceğini, bu nedenle etlik piliç yemlerine katılmadan önce detoksifikasyon işlemi geçirmesinin gerekliliği vurgulanmıştır.

Yapılan bir diğer çalışmada fermente edilmemiş Jatropha tohumu ile fermente edilmiş Jatropha tohumu anti besin maddeleri bakımından karşılaştırılmıştır (Yakubu ve ark., 2017). Araştırıcılar, fermente edilmemiş Jatropha küspesindeki antibesinsel faktörlerin fermente edilenlere göre en yüksek değerleri aldığını, fermente edilmemiş tohumdaki tanin içeriğinin $\% 3$ iken, fermentasyondan sonra \% 0.70 'e düştüğünü, tripsin inhibitör düzeyinin de $\% 22.16$ 'dan \% 4.45'e indiğini ifade etmişlerdir.

\section{Kümes Hayvanlarında Jatropha Bitkisinin Kullanımı}

Bu bitkinin kümes hayvanları beslemede kullanımı ile ilgili olarak farklı çalışmalara rastlanılmıştır. Jatropha, kümes hayvanlarının yemlerine içerdikleri anti besinsel faktörler uzaklaştırıldıktan sonra enerji ve protein kaynağı olarak katılmaktadır. Esansiyel aminoasitlerce ve mineral bakımından zengin içeriğe sahip olmaları nedeniyle alternatif yem kaynağı olarak kullanılma potansiyeline sahip olduğu söylenebilir. Son yıllarda Jatropha'nın kanatlı hayvan karma yemlerinde kullanılmasına yönelik araştırmalar yapılmaktadir. 


\subsection{Etlik piliçlerde yapılan çalışmalar}

Yapılan bir çalışmada, etlik piliçlerin karma yeminde $\% \quad 4$ oranında fermente edilmemiş Jatropha küspesi bulunmasının, aynı düzeyde işlem görmüş Jatropha küspesi ile karşılaştırıldığında canlı ağırlık kazancı bakımından olumsuz bir etki yarattığı ifade edilmiştir (Yakubu ve ark., 2017).

Barros ve ark. (2015), etlik piliçlerin karma yemlerine farklı düzeylerde $\left(25,50\right.$ ve $\left.100 \mathrm{~g} \mathrm{~kg}^{-1}\right)$ fermente edilmemiş Jatropha küspesi katılmasının bağırsak gelişimi ve besin madde sindirilebilirliği üzerine olumsuz etkisinin olduğunu bildirirken; işlem görmüş Jatropha küspesinin etlik piliçlerdeki besin madde yarayışlılığı üzerine yapılan bir diğer çalışmada (Pirgozliev ve ark., 2012), işlem görmüş Jatropha küspesinin tüm mineral madde sindirilebilirliklerinin SFK'dan düşük olduğunu ifade etmiş̧lerdir. Araştırıcılar işlem görmüş Jatropha küspesinin SFK'dan daha yüksek düzeyde azot içerdiğini de tespit etmişlerdir. Sumiati ve ark. (2011), \% 0, 3, 6 ve 9 düzeyinde fermente edilmiş Jatropha küspesi katkısının etkilerini araştırdıkları çalışmada, karma yeme \% 9 düzeyinde fermente edilmiş Jatropha küspesi ilavesinin ölüm oranını azalttığını ifade etmiştir.

Oladunjoye ve ark. (2014), yaptıkları çalışmada etlik piliç karma yemlerine farklı sürelerde fermentasyona birakılan $(7,11$ ve 15 gün) ve farklı oranlarda (\% 4 ve 6 ) ilave ettikleri Jatropha küspesinin, deneme sonu canlı ağırlık değerlerinin kontrol grubuna göre düşük olduğunu tespit etmişlerdir.

Adeyemo ve Oluyede (2015), etlik piliç karma yemlerine Jatropha yaprak ekstraktı ilavesinin performans üzerine bir etkisinin olmadığını tespit ederken; başka bir araştırmada ise Antyev ve ark. (2017), etlik piliç karma yemlerine ilave ettikleri farklı işleme (1slatma, 1sıtma, fermente, kaynatma) metotları uygulanan Jatropha küspesinin performans değerlerini önemli ölçüde etkilediğini bildirmişlerdir. Araştırıcılar \% 10'a kadar fermente edilen Jatropha küspesinin kullanılabileceğini ifade etmiştir. Nesseim ve ark. (2017), yemden yararlanma oranının, uygulamalardan etkilendiğini, Jatropha küspesinin karma yeme ilave edilen oranının artmasına paralel olarak ölüm oranının da arttığını bildirmişlerdir.

Ojediran ve ark. (2019), J. curcas küspesinin katkı düzeyi ile işleme metotlarının, bitirme dönemindeki etlik piliçlerin performans, organ karakteristikleri, hematoloji ve serum parametreleri üzerine olan etkilerini araştırdıkları çalışmalarında, \% 2.5 ve $\% 5.0$ düzeyinde pişmiş yağsı fermente olmuş küspe ve solvent muamelesi yapılmış fermente küspe ile beslenen etlik piliçlerin canlı ağırlık kazancında önemli bir iyileşme olduğunu, kan serumundaki alkalin fosfataz ve kreatinin düzeylerinin istatistiki olarak önemli bulunduğu, bitirme dönemindeki etlik piliçler için önerilen solvent muamelesi yapılmış fermente küspe düzeyinin $\% \quad 5.0$ olduğunu bildirmişlerdir.

\subsection{Yumurta tavuklarında yapılan çalışmalar}

Yumurta tavuklarında bu konuyla ilgili bazı çalışmalar yapılmıştır. Sumiati ve ark. (2012), 2530 haftalık yumurta tavukları üzerinde yapmış oldukları çalışmada, karma yeme fermente J. curcas, selülaz ve fitaz ilave ettikleri çalışmalarında enzimli veya enzimsiz fermente edilmiş $J$. curcas'ın yem tüketimi ve tavuk başına yumurta verimini düşürdüğü ama yumurta ağırlığını etkilemediğini bildirmişlerdir.

Fermente edilmiş Jatropha küspesinin gerek yumurtacı tavuklarda gerekse de etlik piliçlerin kan metabolitleri ve sindirilebilirlikleri üzerine etkisini araştıran Widiyastuti ve ark. (2013), hayvan türünün, büyüme ve protein dönüşümü üzerine olan etkisinin önemli olduğunu; Jatropha küspesinin kan serum trigliserid konsantrasyonu üzerine olan etkisinin önemli bulunduğunu, yumurta tavuklarının beslenmesinde, söz konusu küspenin kullanılması durumunda daha ileri fermantasyon işlemlerinin optimize edilmesinin gerekliliğine dikkat çekmiştir.

\subsection{Bıldırcınlarda yapılan çalışmalar}

Sicaklık işlemi uygulanan ve uygulanmayan Jatropha küspesinin yumurtacı Japon bildırcinı karma yemlerine ilavesinin üreme ve kan biyokimyasal parametresi üzerine etkilerini araştıran Abd El-Hack ve ark. (2017), $100^{\circ}$ C'de 48 saat sicaklik uygulamasının Jatropha küspesindeki toksik etkileri elemine edeceğini ve protein kaynağı olarak üreme ve bağışıklık parametreleri üzerine zararlı bir etkisinin olmayacağını bildirmişlerdir. Araştırıcılar aynı çalışmada yumurta kalite kriterleri bakımından haugh birimi dışında ele alınan tüm ölçütlerin önemsiz olduğunu da belirlemişlerdir (Tablo 3).

Bir başka çalışmada, \% 5 düzeyindeki sıcaklık uygulanmış Jatropha küspesi kullanımının, büyütme dönemindeki bıldırcınlar için güvenli bir düzey olduğu ifade edilirken (Agboola ve Adenuga, 2015); Gross ve ark. (1997), fermente edilmemiş Jatropha küspesi kullanımının ölüm oranını artırdığını, buna karşılık kimyasal uygulama yapılan Jatropha küspesi kullanımının ölüm oranını \% 8 azalttığını bildirmişlerdir. 
Tablo 3. Jatropha küspesinin, 8-16 haftalık yaşlar arasındaki yumurtacı Japon bıldırcınlarının yumurta verim özelliklerine olan etkisi

\begin{tabular}{|c|c|c|c|c|c|}
\hline Parametreler & $\begin{array}{c}\text { Kontrol } \\
\text { grubu }\end{array}$ & $\begin{array}{c}\text { Sicaklik } \\
\text { uygulanmamış } \\
\text { Jatropha } \\
\text { küspesi } \\
\end{array}$ & $\begin{array}{l}\text { Sicaklikla işlem } \\
\text { görmüş Jatropha } \\
\text { küspesi } \\
100^{\circ} \mathrm{C} \text { 'de } 24 \text { saat }\end{array}$ & $\begin{array}{c}\text { Sicaklıkla işlem } \\
\text { görmüş, Jatropha } \\
\text { küspesi } \\
100^{\circ} \mathrm{C} \text { 'de } 48 \text { saat }\end{array}$ & $\mathrm{P}$ \\
\hline Albumin, $\%$ & 63.48 & 59.86 & 62.26 & 58.11 & 0.142 \\
\hline Yumurta sarısı, \% & 23.72 & 26.26 & 25.25 & 26.66 & 0.401 \\
\hline Yumurta kabuğu, \% & 14.00 & 12.77 & 12.60 & 16.19 & 0.116 \\
\hline Yumurta şekil indeksi, \% & 81.73 & 81.62 & 80.94 & 80.90 & 0.965 \\
\hline Kabuk kalınlığı, mm & 0.23 & 0.19 & 0.21 & 0.22 & 0.275 \\
\hline Yumurta sarı indeksi & 37.66 & 36.44 & 39.76 & 39.32 & 0.468 \\
\hline Sarı: Albumin oranı & 0.37 & 0.43 & 0.40 & 0.46 & 0.225 \\
\hline Haugh birimi & $88.03 \mathrm{~b}$ & $87.40 \mathrm{~b}$ & $88.61 \mathrm{~b}$ & $91.55 \mathrm{a}$ & $0.010^{*}$ \\
\hline
\end{tabular}

P: Önemlilik düzeyi, *: İstatistiki açıdan $\mathrm{p}<0.05$ düzeyinde önemli

\section{Sonuçlar}

Jatropha ve küspesi, kanatlı hayvan beslemede kullanılmakta olup; hayvan besleme açısından besin madde içeriği yüksek olması nedeniyle, soya fasülyesi küspesinin yerine kullanılabilecek alternatif bir yem maddesi olabilir. Türkiye'de protein ve enerji içeren alternatif yem kaynaklarının araştırılması ve kullanılması, kanatlı hayvan sektöründe et ve yumurta maliyetlerinin azalmasına yol açacaktır. Bu nedenle Jatropha, ucuza alınabilecek yeni alternatif yem kaynaklarından birisi olup; Türkiye'de bu konu ile ilgili çalışmalara önem verilmesi gerekmektedir.

\section{Kaynaklar}

Abd El-Hack, M.E., Alagawany, M., El-Sayed, S.A.A., Fowler, J., 2017. Influence of dietary inclusion of untreated or heat-treated $\mathrm{JM}$ on productive and reproductive performances and biochemical blood parameters of laying Japanese quail. Poultry Science, 96(8): 2761-2767.

Abou-Arab, A.A., Abu-Salem, F.M., 2010. Nutritional quality of Jatropha curcas seeds and effect of some physical and chemical treatments on their antinutritional factors. African Journal of Food Science, 4(3): 93-103.

Adeyemo, G.O., Oluyede, F.A., 2015. Dietary inclusion of ethanolic extracts of Jatropha curcas on the performance and carcass characteristics of broiler chickens. American Journal of Experimental Agriculture, 8(2): 130-136.

Agboola, A.F., Adenuga, A.A., 2015. Performance and organ histopathology of growing Japanese quails (Coturnix coturnix Japonica) fed heat treated Jatropha seed cake substituted for soyabean meal. Tropical Animal Production Investigation, 18: 1-8.

Annongu, A.A., Belewu, M.A., Joseph, J.K., 2010. Potentials of Jatropha curcas seeds as substitute protein in nutrition of poultry. Research Journal of Animal Sciences, 4(1): 1-4.

Antyev, M., Yakubu, B., Aliyara, Y.H., Wafar, R.J., 2017. Effects of processing methods of Jatropha curcas seed meal on growth performance and blood profile of broiler finisher chickens. Asian Research Journal of Agriculture, 4(4): 1-9.

Asuk, A.A., Agiang, M.A., Dasofunjo, K., Willie, A.J., 2015. The biomedical significance of the phytochemical, proximate and mineral compositions of the leaf, stem bark and root of Jatropha curcas. Asian Pacific Journal of Tropical Biomedicine, 5(8): 650-657.

Barros, C.R., Rodrigues, M.A.M., Nunes, F.M., Kasuya, M.C.M., Daluz, J.M.R., Alves, A., Ferreira, I.M.M., Pinheiro, V., Mourao, J.I., 2015. The effect of Jatropha curcas seed meal on growth performance and internal organs development and lesions in broiler chickens. Brazilian Journal of Poultry Science, 17: 1-6.

Cheeke, P.R., 1998. Natural toxicants in feeds, forages and poisonous plants. Interstate Publishers, Inc.

Gross, H., Foidl, G., Foidl, N., 1997. Detoxification of Jatropha curcas press cake and oil and feeding experiments on fish and mice. In: GM. Gübitz, M. Mittelbach and M. Trabi (Eds.), Biofuel and Industrial Product from Jatropha curcas. DBVVerlag, Graz.

Gutierrez-Orozco, F., Failla, M.L., 2013. Biological activities and bioavailability of mangosteen xanthones: A critical review of the current evidence. Nutrients, 5(8): 3163-3183.

Heuzé, V., Tran, G., Edouard, N., Renaudeau, D., Bastianelli, D., Lebas, F., 2016. Jatropha (Jatropha sp.) Kernel Meal and Other Jatropha Products. Feedipedia, A Programme by INRA, CIRAD, AFZ and FAO (http://www.feedipedia.org/node/620).

Jongschaap, R.E.E., Corré, W.J., Bindraban, P.S., Brandenburg, W.A., 2007. Claims and Facts on Jatropha curcas L. Plant Research International B.V., Wageningen, Stichting Het Groene Woudt, Laren.

Makkar, H.P.S., Becker, K., 1997. Jatropha curcas toxicity: Identification of toxic principles. In: 5th International Symposium on Poisonous Plants, T. Garland and A.C. Barr (Eds.), May 19-23, San Angelo, Texas, USA.

Marroquin, E., Blanco, J., Granados, S., Caceres, A., Morales, C., 1997. Clinical trial of Jatropha curcas 
sap in the treatment of common warts. Fitoterapia, 68(2): 160-162.

Michael, K.G., Sogbesan, O.A., Onyia, L.U., Shallangwa, S.M., 2019. Nutritional evaluation of processed Jatropha curcas seed meals. Direct Research Journal of Agriculture Food Science, 7(6): 131-136.

Nesseim, T.D.T., Dieng, A., Mergeai, G., Hornick, J.L., 2017. Effects of defatting combined or not to heating of Jatropha curcas kernel meal on feed intake and growth performance in broiler chickens and chicks in Senegal. Tropicultura, 35(3): 149-157.

Obun, C.O., Lalabe, B.C., Wafar, R.J., 2016. Comparative evaluation of raw and processed Jatropha curcas seed meal on performance of cockerel chicks. FUW Trends in Science \& Technology Journal, 1(2): 388-390.

Ojediran, T.K., Ajayi, A.F., Emiola, A.I., 2019. Effects of processing methods and levels of inclusion of Jatropha curcas kernel meal on performance, organ characteristics, haematology and serum chemistry of finisher broiler chickens. Journal of Agricultural Sciences, 64(1): 69-83.

Ojo, R.J., Oguche, P.I., Kube, G.D., Udzer, T.E., 2013. Effect of Jatropha curcas supplemented diet on broilers. Scholars Academic Journal of Biosciences, 1(6): 329-336.

Oladunjoye, I.O., Ojediran, T., Aringbangba, C., Akinrinlade, O.S., Opakunle, O.G., 2014. Effects of inclusion level and length of fermentation on the utilization of Jatropha (Jatropha curcas L.) seed cake by broiler chickens. International Journal of Current Microbiology Applied Science, 3(7): 44- 54.

Pasaribu, T., Wina, E., Tangendjaja, B., Iskandar, S., 2010. Performance of broiler chicken fed physically and chemically treated Jatropha (Jatropha curcas) seed meal. Indonesian Journal of Agriculture, 3(2): 121-126.

Pirgozliev, V., Jesson, C., Brooker, J., Rose, S.P., 2012. The nutrient availability of processed Jatropha curcas kernel meal for broiler chickens. Arch Geflügelk, 76(4): 230-233.
Pomalégni, S.C.B., Gbemavo, D.S.J.C., Gnanglè, P.C., Djossou, S.R., Kenis, M., Babatounde, S., Glèlè Kakai, L.R., Mensah, G.A., 2018. Seed cake of Jatropha curcas L. potential substrate to produce maggots as feed for reared monogastric animals. The Journal of Animal \& Plant Sciences, 28(6): 15911596.

Saeed, M., Arain, M.A., Arif, M., Lagawany, M., Abd El-Hack, M.E., Kakar, M.U., Manzoor, R., Erdenee, S., Chao, S., 2017. Jatropha (Jatropha curcas) meal is an alternative protein source in poultry nutrition. World's Poultry Science Assocation, 73(4): 783-790.

Sumiati, F., Hermana, W., Sudarman, A., 2011. Performa ayam broiler yang diberi ransum mengandung bungkil biji jarak pagar (Jatropha curcas L.) hasil fermentasi menggunakan rhizopus oligosporus. Media Peternakan, 34(2): 117-125.

Sumiati, S., Mutia, R., Darmansyah, A., 2012. Performance of layer hen fed fermented Jatropha curcas L. meal supplemented with cellulase and phytase enzyme. Journal of the Indonesian Tropical Animal Agriculture, 37(2): 108-114.

Sumiati, Y., Asuti, D.A., Suharti, S., 2009. Feeding fermented Jatrpoha curcas L. meal supplemented with cellulase and phytase to kampong chicken. The 1st International Seminar on Animal Industry, Facuty of Animal Science, Bogor Agricultural University, November 23-24th., Bogor, pp. 191-197.

Syed, D.N., Chamcheu, J.C., Adhami, V.M., Mukhtar, H., 2013. Pomegranate extracts and cancer prevention: Molecular and cellular activities. Anticancer Agents in Medicinal Chemistry, 13(8): 1149-1161.

Yakubu, B., Aliyara, Y.H., Antyev, M., Mbahi, T.F., 2017. Effect of fermented Jatropha (Jatrpoha curcas) seed meal on growth performance, carcass and internal organs evaluation of broiler finisher chicks. Greener Journal of Animal Breeding and Genetics, 3(1): 001-008.

Widiyastuti, T., Prayitno, C.H., Iriyanti, N., 2013. Digestibility and blood metabolite profiles of chicken fed fermented Jatropha seed meal. Animal Production, 15(2): 98-105. 